\title{
Evaluation of coexistence of Alzheimer's disease in idiopathic normal pressure hydrocephalus using ELISA analyses for CSF biomarkers
}

Tae Sung Lim', Jun Young Choi', Sun Ah Park², Young Chul Youn ${ }^{3}$, Hyun Young Lee', Byung Gon Kim', In Soo Joo ${ }^{1}$, Kyoon Huh ${ }^{1}$ and So Young Moon ${ }^{1 *}$

\begin{abstract}
Background: We investigated levels of the $\beta$-amyloid 1-42 (Aß42), total tau protein (T-tau) and tau phosphorylated at position threonine 181 (P-tau) in cerebrospinal fluid (CSF) of idiopathic normal pressure hydrocephalus (iNPH) patients and tried to find their clinical implications in the evaluation and treatment of iNPH.

Method: Twenty-five possible iNPH patients were prospectively enrolled and their CSF was collected to analyze levels of AB42, T-tau and P-tau using ELISA method. Gait disturbance, urinary incontinence, and cognitive impairment were semi-quantified and detailed neuropsychological (NP) test was performed.

Result: Eight iNPH patients were classified into the lower CSF A 42 group and 17 patients were classified into the higher CSF A 422 group. There was no difference in the iNPH grading score and its improvement after LP between the two groups. The lower CSF A 42 group showed more deficits in attention, visuospatial function and verbal memory in the baseline NP test and less improvement in phonemic categorical naming and frontal inhibitory function after LP.
\end{abstract}

Conclusions: Our study suggested that concomitant AD in iNPH patients might contribute to lumbar puncture or shunt unresponsiveness, especially in the field of cognitive dysfunction.

Keywords: Normal pressure hydrocephalus, Alzheimer's disease, Cerebrospinal fluid, Lumbar puncture, Neuropsychological tests

\section{Background}

Idiopathic normal pressure hydrocephalus (iNPH) is characterized by a clinical triad of symptoms including cognitive impairment, gait difficulty, and urinary incontinence along with ventricular enlargement in brain imaging [1,2]. It is a potentially reversible cause of cognitive and motor impairment in older adults using ventriculo-peritoneal (VP) shunt or ventriculo-atrial (VA) shunt operation. While treatment with VP shunts is widely used and effective, the complication rate is high [3] and the risk factors for shunt unresponsiveness are poorly understood. A possible contributor to shunt unresponsiveness is the

\footnotetext{
* Correspondence: symoon.bv@gmail.com

'Department of Neurology, School of Medicine, AjouUniversity, 5 San, Woncheon-dong, Yongtong-gu, Suwon-si, Kyunggi-do 442-749, Republic of Korea

Full list of author information is available at the end of the article
}

presence of comorbid neurologic conditions that are common in the aged, such as Alzheimer's disease (AD) [4].

$\mathrm{AD}$ and $\mathrm{iNPH}$ have different pathomechanism, but recent studies pointed out common pathomechanism between the two diseases $[5,6]$. However there is still controversy about the clinical implications of the coexistence of AD pathology in $\mathrm{NPH}$ patients. Some suggested that $\mathrm{AD}$ was only a bystander and the rate of coexistence of AD was similar to that of normal population [7-9] while the others reported the poor shunt response was possibly due to AD pathology $[4,10]$. Since the introduction of ELISA method to detect cerebrospinal fluid (CSF) biomarkers for $\mathrm{AD}$, there have been many studies about the differential role of levels of the $\beta$-amyloid 1-42 (A $\beta 42)$, $\mathrm{T}$-tau protein (T-tau) and tau phosphorylated at position threonine 181 (P-tau) in CSF of iNPH patients [11-15]. However, there are still debates about the level of each 
biomarker in two diseases and the implication of their changes $[16,17]$.

The aim of this study was to investigate levels of the A $\beta 42$, T-tau and P-tau in CSF of iNPH patients and describe the clinical implications in the evaluation and treatment of iNPH.

\section{Methods}

Participants

Among patients who visited the Department of Neurology at the Ajou Medical Center, Suwon, Korea from March 2010 to February 2012, we consecutively recruited 25 patients who satisfied the criteria for possible iNPH. All patients had had brain MRIs and an LP. The clinical criteria for possible iNPH included following: (1) MRI showing ventricular enlargement (2) Any one symptom from clinical triad (gait disturbance, cognitive deficit or urinary disturbance) which was considered as a symptom compatible with iNPH by the clinician [2]. After making a diagnosis of iNPH, one or two LPs were performed to drain 30 to $50 \mathrm{ml}$ of the CSF and $10 \mathrm{ml}$ of CSF was collected to evaluate biomarkers for $\mathrm{AD}$. The diagnosis of $\mathrm{iNPH}$ was made independently from the patients' response to the LPs.

The CSF of $17 \mathrm{AD}$ patients and 10 normal control subjects which were collected and stored previously at two other hospitals (S.C.H.U.H. and C.A.U.H.) was tested to get a cutoff value of the coexistence of $\mathrm{AD}$. All $\mathrm{AD}$ patients met the criteria for probable $\mathrm{AD}$ as proposed by the National Institute of Neurological and Communicative Diseases and Stroke and Alzheimer's disease and Related Disorders Association (NINCDS-ADRDA) [18]. All normal control subjects scored in each cognitive domain test higher than the cutoff value. The cutoff values for each test score were represented as a -1.0 SD below the published norms for their age and education group [19].

We excluded patients with a history of significant hearing or visual impairment that could render interview participation difficult, as well as those with a history of other neurological disorders (e.g., idiopathic Parkinson's disease, dementia with Lewy bodies, or active epilepsy), psychiatric illnesses (e.g., schizophrenia, mental retardation, major depression, or mania), those taking psychotropic medications, and those with a history of significant alcohol and/or other substance abuse. Each patient provided written informed consent. If patients had impaired decisional capacity, caregivers provided consent and patients provided assent. This study was approved by the Ajou Institutional Review Board.

\section{Evaluation of iNPH symptoms}

An iNPH scale modified from Larsson et al. [20] and Krauss et al. [21] that assessed gait $[1=$ normal, $2=$ walk without any assistive device but insecure, $3=$ walk with cane, $4=$ walk with bimanual support (walker), $5=$ walk aided by an assistant, $6=$ wheelchair-bounded], urinary disturbance $(0=$ normal, $1=$ sporadic $(1-3$ or more times per week but less than once per day) incontinence or urge phenomena, 2 = frequent ( 1 or more times per day) incontinence or urge phenomena, and $3=$ no or minimal control of bladder function) and cognitive deficit $(0=$ normal, $1=$ minimal attention or memory deficits, $2=$ considerable attention or memory deficits but oriented to situational context, and $3=$ not or only marginally oriented to situational context) was used to characterize and grade the clinical syndrome. Patients were evaluated both before and 4 to 6 hours after the LP.

\section{Sample collection}

All participants underwent LP in the L3-4 or L4-5 interspace to drain $30 \sim 50 \mathrm{ml}$ of CSF to evaluate response to LP from 10:00 to 12:00. During the procedure, $10 \mathrm{ml}$ of CSF was collected in polypropylene tubes after discarding the first $3 \sim 4 \mathrm{ml}$. Bloody or cloudy samples were rejected. No serious adverse events were reported. The samples were immediately centrifuged for 15 minutes at $2,000 \mathrm{rpm}$ to remove cells and aliquots were stored in polypropylene tubes and immediately frozen at $-80^{\circ} \mathrm{C}$ until analysis. They were thawed just before analysis.

\section{ELISA methods}

CSF T-tau concentration was determined using a sandwich enzyme-linked immunosorbent assay ([ELISA] Innotest hTAU-Ag, Innogenetics, Ghent, Belgium) specifically constructed to measure all tau isoforms irrespective of phosphorylation status, as previously described [22]. P-tau was measured using a sandwich ELISA method (Innotest Phospho-Tau[181P]), as previously described [23]. A $\beta 42$ levels were determined using a sandwich ELISA (Innotest $\beta$-amyloid [1-42]), specifically constructed to measure amyloid- $\beta$ containing both the 1 st and 42 nd amino acids, as previously described [24]. All biomarker levels were measured in duplicate according to the manufacturer's instructions. The CSF samples of iNPH patients were analyzed twice using different aliquot.

\section{Magnetic resonance image}

The Evans index and white matter hyperintensity were assessed using MRI. The Evans index was defined as the maximal frontal horn ventricular width divided by the transverse inner diameter of the skull and signifies ventriculomegaly if it is 0.3 or greater [2]. White matter hyperintensity was evaluated by the method designed by Clinical Research for Dementia of South Korea Study (CREDOS). Both periventricular (1-3) and deep (1-3) white matter hyperintensities were assessed [25]. Each longest-diameter white matter change around the lateral ventricles (capping or banding on the periventricular areas) or deep in white matter (especially the centrum semiovale) were evaluated separately. The deep white 
Table 1 Demographic and clinical characteristics of the subject groups $(\mathrm{N}=52)$

\begin{tabular}{|c|c|c|c|c|c|c|}
\hline & iNPH & $A D$ & Control & $p_{1}$ & $p_{2}$ & $p_{3}$ \\
\hline n (M/F) & $25(12 / 13)$ & $17(10 / 7)$ & $10(3 / 7)$ & & & \\
\hline Age, yr & $73.3 \pm 7.0$ & $72.2 \pm 10.0$ & $63.0 \pm 6.7$ & 0.924 & $0.029 *$ & 0.090 \\
\hline Education, yr & $8.5 \pm 5.2$ & $6.1 \pm 5.6$ & $5.5 \pm 5.2$ & 0.469 & 0.498 & 0.970 \\
\hline K-MMSE & $19.5 \pm 6.9$ & $18.3 \pm 2.1$ & $26.6 \pm 2.5$ & 0.832 & $0.042^{*}$ & $0.029 *$ \\
\hline$A \beta 42, \mathrm{pg} / \mathrm{ml}$ & $579.8 \pm 182.3$ & $409.2 \pm 166.1$ & $691.8 \pm 212.7$ & $0.013^{*}$ & 0.241 & $0.001 *$ \\
\hline T-tau, pg/ml & $131.9 \pm 77.6$ & $259.6 \pm 161.5$ & $196.9 \pm 114.4$ & $0.003^{*}$ & 0.312 & 0.382 \\
\hline P-tau, pg/ml & $27.0 \pm 9.6$ & $51.3 \pm 28.3$ & $43.0 \pm 28.5$ & $0.002^{*}$ & 0.123 & 0.597 \\
\hline
\end{tabular}

Continuous variables are presented as mean \pm standard deviation. iNPH: Idiopathic Normal Pressure Hydrocephalus; AD: Alzheimer's Disease; M: Male; F: Female; K-MMSE: Korean version of Mini Mental Status Exam; $p_{1}$ : $p$-value between iNPH and AD; $p_{2}$ : $p$-value between iNPH and control; $p_{3}$ : $p$-value between AD and control. ${ }^{*} \mathrm{p}<0.05$.

matter changes were rated as $1(<10 \mathrm{~mm}), 2(\geq 10 \mathrm{~mm}$, $<25 \mathrm{~mm})$, or $3(\geq 25 \mathrm{~mm}$ ) and periventricular white matter changes were rated as $1(<5 \mathrm{~mm})$ or $2(\geq 5 \mathrm{~mm},<10 \mathrm{~mm})$, or $3(\geq 10 \mathrm{~mm})$. Hippocampal atrophy was graded by Scheltens' method [26].

\section{Neuropsychological tests}

Neuropsychologists assessed participants' cognitive functioning via the extensive Seoul Neuropsychological Screening Battery (SNSB) [19] covering five specific cognitive domains, as follows.
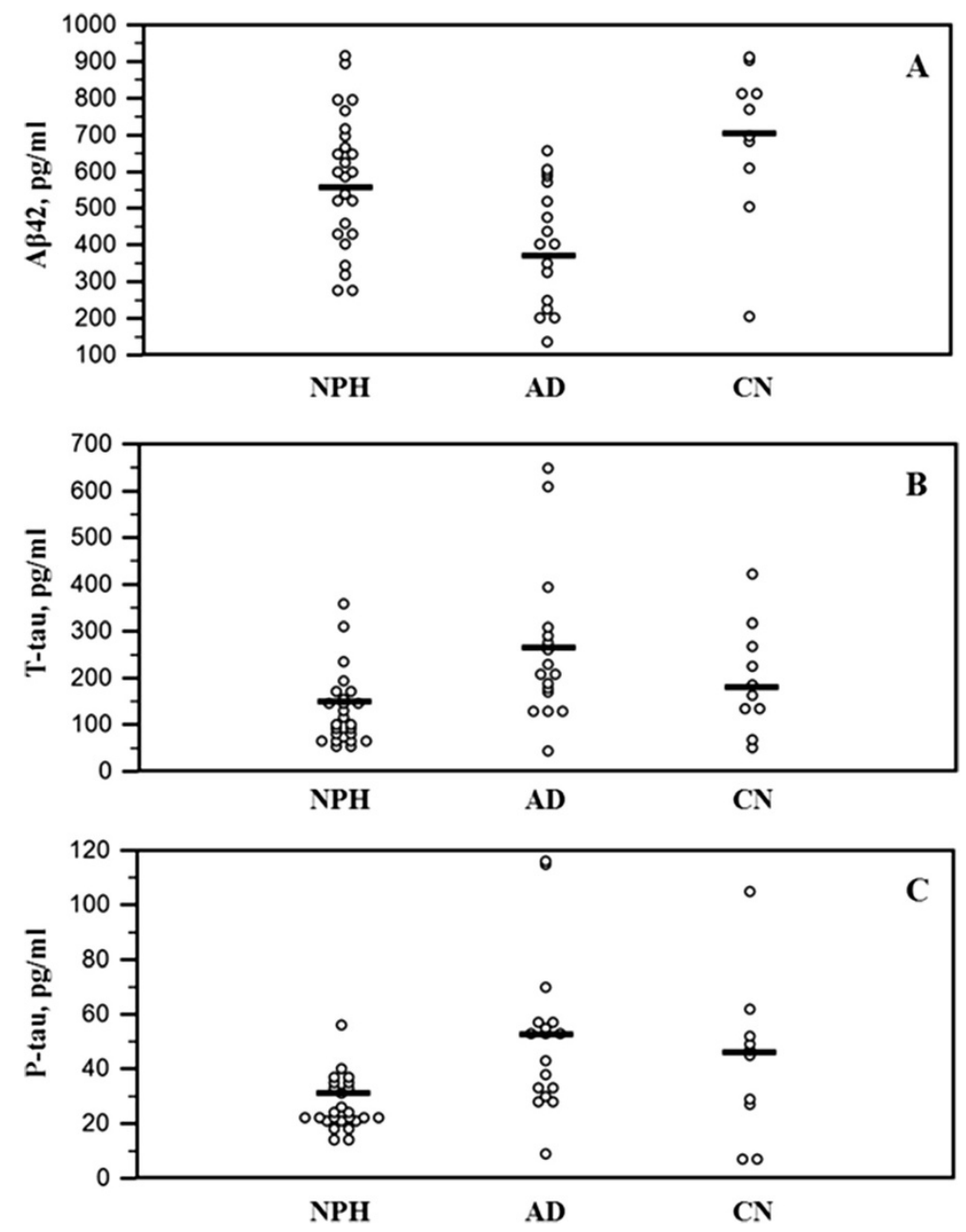

Figure 1 Levels of CSF A 342 (A), T-tau (B) and P-tau (C) in the subject groups. 
(1) The attention and working memory assessment used the digit span forward and backward tests.

(2) The language function assessment employed the Korean version of the Boston Naming Test (K-BNT) [27].

(3) The visuospatial function assessment was the patient's copy score of the Rey Complex Figure Test (RCFT), neuropsychological assessment in which examinees are asked to reproduce a complicated line drawing, first by copying and then from memory.

(4) Memory function was divided into verbal and visual memory. We assessed verbal memory by means of the Seoul Verbal Learning Test (SVLT), the Korean version of the revised Hopkins Verbal Learning Test (HVLT-R), testing participants on the immediate recall, delayed recall, and recognition tasks. To assess visual memory, we tested participants on the RCFT's immediate recall, delayed recall, and recognition tasks.

(5) To assess frontal lobe functioning, we used the contrasting program, go-no go, the semantic and phonemic aspects of the Controlled Oral Word Association Test (COWAT) and Stroop test.

\section{Statistical analysis}

We used chi-square, analysis of variance (ANOVA), and Kruskal-Wallis tests to compare demographic data of each group and analysis of covariance (ANCOVA) to compare clinical data and the neuropsychological test percentile scores adjusted by the age, gender and years of education of normative data from general population. Post-hoc analyses with Least Significant Difference (LSD) method were performed for between-group comparisons. Intraclass correlation coefficient was calculated to show the test-retest reliability of ELISA. Receiver operating characteristics (ROC) curve analysis was used to identify the cut-off levels with the optimal combination of specificity and sensitivity. Mann-Whitney test was used to compare the scores of neuropsychological tests between the subgroups of iNPH patients, adjusted for age, sex and duration of education. All statistical analyses were performed using SPSS 13.0 (SPSS Inc, Chicago, IL, USA). Null hypotheses of no difference were rejected if $\mathrm{p}$-values were less than .05 .

\section{Results}

\section{Demographic and clinical characteristics of the subject} groups

Demographic and clinical characteristics and results of statistical analyses are summarized in Table 1 and plotted in Figure 1. The age of AD group was significantly older than the control group $(p=0.029)$. The intraclass correlation coefficient of $\mathrm{A} \beta 42$, T-tau and P-tau were 0.922, 0.908 and 0.960 , respectively. The mean value of the two test results of each analysis was used for statistical analyses. CSF A $\beta 42$ level of AD was significantly lower than iNPH $(p=0.013)$ and control group $(p=0.001)$ after adjustment for age, sex and duration of education. CSF T-tau and P-tau levels were significantly higher in AD than iNPH $(p=0.003$ and $\mathrm{p}=0.002$, respectively).

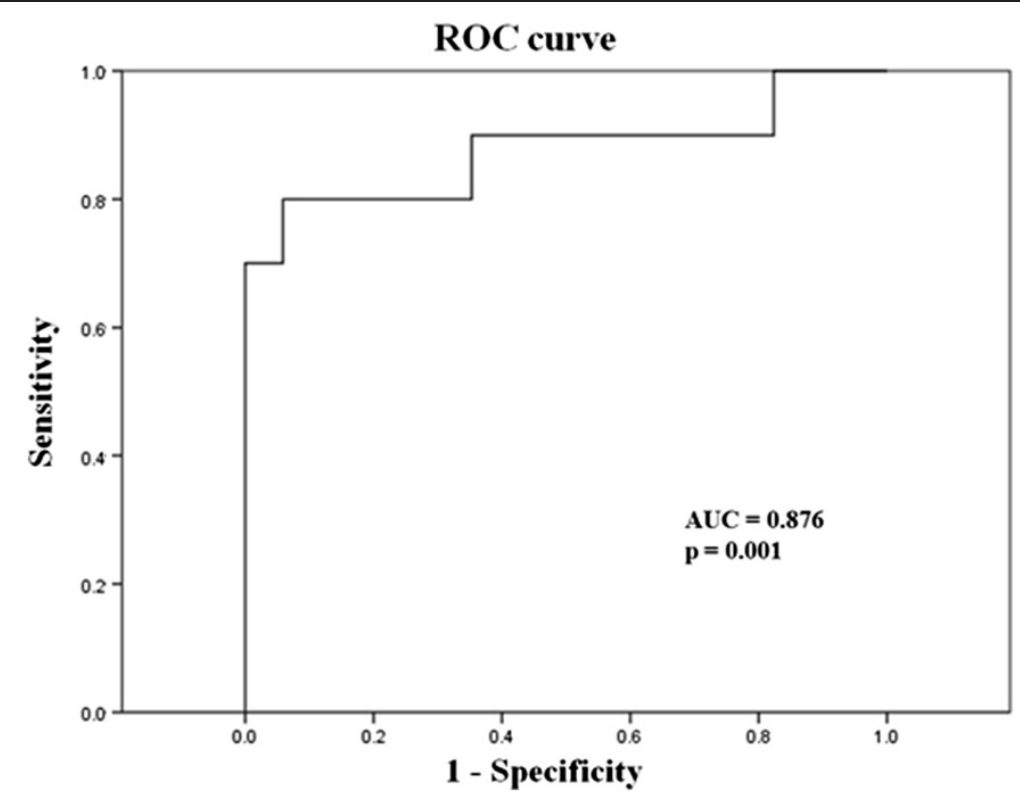

Figure 2 Receiver operating characteristic (ROC) curve of CSF A 342 for discrimination between the control and AD patient groups. 


\section{Classification of the iNPH patients according to ELISA results}

To determine a cut-off level of the coexistence of AD in iNPH patients, ROC curve analysis was performed. CSF A 342 was used because it was the only biomarker which was significantly different between AD and control group. The area under the curve was 0.876 with p-value of 0.001 (Figure 2). Following recommendations of previous studies, sensitivity more than $85 \%$ was selected in the determination of cutoff level of $490 \mathrm{pg} / \mathrm{ml}$, similar to the previous study (482 $\mathrm{pg} / \mathrm{ml})$ [28].

\section{Demographic and clinical characteristics of the iNPH patient subgroups}

Eight iNPH patients were classified into the lower CSF A 342 group and 17 patients were classified into the higher CSF $A \beta 42$ group. We statistically compared the lower CSF A $\beta 42$ group and the higher CSF A $\beta 42$ group using the Mann-Whitney test. There was no difference in age, sex and duration of education. Among the variables tested, hippocampal atrophy grade was significantly higher in the lower CSF A $\beta 42$ group than the higher CSF A 342 group $(p=0.02)$. There was no difference in the iNPH grading score and improvement rate after LP between the two groups (Table 2).

\section{Neuropsychological test results of the iNPH patient subgroups according to CSF $A \beta 42$ level}

A total of 18 iNPH patients underwent detailed neuropsychological tests as an initial evaluation before CSF drainage. Seven patients belonged to the lower CSF A $\beta 42$ group and 11 belonged to the higher CSF A $\beta 42$ group. Among the neuropsychological test scores, the lower CSF A 342 group had a lower score in Digit span forward test $(\mathrm{p}=0.018)$, RCFT copy test $(\mathrm{p}=0.043)$ and SVLT immediate recall test $(\mathrm{p}=0.009)$ after adjustment for age, sex and duration of education (Table 3, A).

In a subset analysis of 10 patients who underwent follow-up neuropsychological tests after CSF drainage, the lower CSF A 342 group showed significantly less improvement in phonemic COWAT $(\mathrm{p}=0.008)$ and color reading test in Stroop test $(\mathrm{p}=0.018)$ after LP compared to the higher CSF A $\beta 42$ group after adjustment for age, sex and duration of education. The mean interval between the first and the second neuropsychological test was $13.2 \pm 9.4$ days (Table $3, \mathrm{~B}$ ).

\section{Discussion}

Although there have been a few studies about the coexistence of $\mathrm{AD}$ in $\mathrm{iNPH}$ patients and its clinical implication, to the best of our knowledge, this is the first study which reports the difference in detailed neuropsychological tests before and after CSF drainage according to CSF biomarkers for AD. The major findings of this study
Table 2 Demographic and clinical data of the iNPH patient subgroups by CSF $A \beta 42$ level $(N=25)$

\begin{tabular}{|c|c|c|c|}
\hline & $\begin{array}{l}\text { Lower CSF } \\
\mathrm{A} \beta 42\end{array}$ & $\begin{array}{l}\text { Higher CSF } \\
\mathrm{A} \beta 42\end{array}$ & $p$-value \\
\hline$n(M / F)$ & $8(3 / 5)$ & $17(9 / 8)$ & 0.673 \\
\hline Age, yr & $76.1 \pm 7.3$ & $72.0 \pm 6.7$ & 0.187 \\
\hline Education, yr & $7.7 \pm 5.6$ & $8.7 \pm 5.2$ & 0.687 \\
\hline K-MMSE & $16.8 \pm 6.6$ & $20.8 \pm 6.9$ & 0.193 \\
\hline Disease duration, day & $724.1 \pm 513.6$ & $769.4 \pm 520.4$ & 0.857 \\
\hline $\mathrm{A} \beta 42, \mathrm{pg} / \mathrm{ml}$ & $368.7 \pm 72.3$ & $679.1 \pm 121.7$ & $<0.001^{*}$ \\
\hline T-tau, pg/ml & $145.7 \pm 103.9$ & $125.3 \pm 64.6$ & 0.551 \\
\hline P-tau, pg/ml & $28.2 \pm 13.8$ & $26.4 \pm 7.3$ & 0.682 \\
\hline Evans ratio & $0.34 \pm 0.02$ & $0.36 \pm 0.03$ & 0.277 \\
\hline DWMH & $1.6 \pm 0.9$ & $1.5 \pm 0.8$ & 0.804 \\
\hline PVWMH & $2.0 \pm 0.7$ & $1.9 \pm 0.7$ & 0.856 \\
\hline Hippocampal atrophy & $1.6 \pm 0.9$ & $0.7 \pm 0.6$ & $0.020^{*}$ \\
\hline Pre-gait score & $2.75 \pm 1.48$ & $2.59 \pm 1.54$ & 0.807 \\
\hline Pre-urinary score & $1.00 \pm 1.06$ & $0.94 \pm 0.96$ & 0.892 \\
\hline Pre-cognition score & $1.50 \pm 0.75$ & $1.41 \pm 0.79$ & 0.795 \\
\hline Pre-iNPH score sum & $4.13 \pm 2.94$ & $3.94 \pm 2.86$ & 0.883 \\
\hline Post-gait score & $2.00 \pm 1.69$ & $2.00 \pm 1.11$ & 1.000 \\
\hline Post-urinary score & $0.63 \pm 1.06$ & $0.47 \pm 0.80$ & 0.689 \\
\hline Post-cognition score & $1.38 \pm 0.91$ & $1.12 \pm 0.78$ & 0.474 \\
\hline Post-iNPH score sum & $3.00 \pm 3.38$ & $2.65 \pm 2.14$ & 0.753 \\
\hline Gait score improvement & $0.75 \pm 0.70$ & $0.59 \pm 0.87$ & 0.651 \\
\hline $\begin{array}{l}\text { Urinary score } \\
\text { improvement }\end{array}$ & $0.38 \pm 0.74$ & $0.47 \pm 0.71$ & 0.761 \\
\hline $\begin{array}{l}\text { Cognition score } \\
\text { improvement }\end{array}$ & $0.13 \pm 0.35$ & $0.29 \pm 0.47$ & 0.377 \\
\hline iNPH score improvement & $1.25 \pm 1.48$ & $1.29 \pm 0.68$ & 0.950 \\
\hline
\end{tabular}

Continuous variables are presented as mean \pm standard deviation. iNPH: Idiopathic Normal Pressure Hydrocephalus; AD: Alzheimer's Disease; M: Male; F: Female; K-MMSE: Korean version of Mini Mental Status Exam; PVWMH: Periventricular White Matter Hyperintensity; DWMH: Deep White Matter Hyperintensity. ${ }^{*} p<0.05$.

were as follows: (1) All three biomarkers for AD diagnosis were significantly different between $\mathrm{AD}$ and iNPH. (2) There was no difference in demographic and clinical characteristics including the response to CSF drainage using iNPH grading system between the lower CSF $A \beta 42$ group and the higher CSF $A \beta 42$ group. (3) Comparison of initial neuropsychological tests showed deficits in attention, visuospatial function and verbal memory are more prominent in the lower CSF $A \beta 42$ group than the higher CSF A $\beta 42$ group. (4) Neuropsychological performance improvement before and after CSF drainage were significantly less in phonemic categorical naming and frontal inhibitory function in the lower CSF A $\beta 42$ group than the higher CSF $A \beta 42$ group.

In the comparison of $\mathrm{A} \beta 42, \mathrm{~T}$-tau and $\mathrm{P}$-tau between iNPH and AD, A 342 was lower and T-tau and P-tau were 
Table 3 Neuropsychological test results of the iNPH patient subgroups by CSF A 342 level before CSF drainage $(\mathrm{N}=18, \mathrm{~A})$ and change before and after CSF drainage $(\mathrm{N}=10, \mathrm{~B})$

\begin{tabular}{|c|c|c|c|c|c|c|}
\hline & \multicolumn{3}{|c|}{ (A) } & \multicolumn{3}{|c|}{ (B) } \\
\hline & $\begin{array}{l}\text { Lower CSF A } 442 \\
\qquad(n=7)\end{array}$ & $\begin{array}{l}\text { Higher CSF A } 442 \\
\quad(n=11)\end{array}$ & $\mathbf{P}$ & $\begin{array}{l}\text { Lower CSF A } 342 \\
\qquad(n=5)\end{array}$ & $\begin{array}{l}\text { Higher CSF } A \beta 42 \\
\qquad(n=5)\end{array}$ & $\mathrm{p}$ \\
\hline \multicolumn{7}{|l|}{ Attention } \\
\hline Digit span forward test & $4.7 \pm 1.1$ & $6.2 \pm 1.4$ & $0.018^{*}$ & $0.2 \pm 1.3$ & $-0.6 \pm 0.8$ & 0.131 \\
\hline Digit span backward test & $2.0 \pm 1.5$ & $2.7 \pm 1.1$ & 0.271 & $0.0 \pm 0.7$ & $-0.2 \pm 0.8$ & 0.911 \\
\hline \multicolumn{7}{|l|}{ Language function } \\
\hline K-BNT & $25.3 \pm 6.6$ & $36.1 \pm 14.3$ & 0.157 & $2.4 \pm 6.5$ & $0.6 \pm 3.6$ & 0.602 \\
\hline \multicolumn{7}{|l|}{ Visuospatial function } \\
\hline RCFT Copy & $12.8 \pm 10.7$ & $23.7 \pm 12.5$ & $0.043^{*}$ & $0.1 \pm 4.5$ & $-1.0 \pm 2.1$ & 0.577 \\
\hline \multicolumn{7}{|l|}{ Memory function } \\
\hline SVLT immediate recall & $6.8 \pm 1.9$ & $13.3 \pm 3.6$ & $0.009 *$ & $2.0 \pm 3.0$ & $4.2 \pm 3.8$ & 0.117 \\
\hline SVLT delayed recall & $0.1 \pm 0.3$ & $1.8 \pm 2.0$ & 0.204 & $0.0 \pm 0.0$ & $2.0 \pm 1.8$ & 0.054 \\
\hline SVLT recognition & $15.5 \pm 2.9$ & $15.9 \pm 4.0$ & 0.820 & $-1.0 \pm 4.1$ & $1.4 \pm 2.8$ & 0.602 \\
\hline RCFT immediate recall & $2.9 \pm 4.3$ & $7.9 \pm 6.7$ & 0.129 & $-0.8 \pm 2.5$ & $2.2 \pm 3.5$ & 0.245 \\
\hline RCFT delayed recall & $1.8 \pm 2.8$ & $6.6 \pm 6.2$ & 0.232 & $0.3 \pm 2.3$ & $3.0 \pm 3.2$ & 0.245 \\
\hline RCFT recognition & $16.0 \pm 3.3$ & $16.9 \pm 3.1$ & 0.480 & $-2.6 \pm 3.2$ & $2.0 \pm 3.0$ & 0.465 \\
\hline \multicolumn{7}{|l|}{ Frontal function } \\
\hline Contrasting program & $15.0 \pm 8.3$ & $14.2 \pm 9.1$ & 0.691 & $-0.2 \pm 0.4$ & $0.2 \pm 0.4$ & 0.180 \\
\hline Go-no go & $9.6 \pm 10.2$ & $11.0 \pm 9.1$ & 0.499 & $3.2 \pm 8.9$ & $2.8 \pm 6.2$ & 0.451 \\
\hline Semantic COWAT & $6.3 \pm 3.9$ & $8.8 \pm 6.1$ & 0.269 & $-1.4 \pm 3.3$ & $5.4 \pm 6.1$ & 0.117 \\
\hline Phonemic COWAT & $10.0 \pm 6.0$ & $14.4 \pm 11.4$ & 0.926 & $-1.0 \pm 1.7$ & $5.4 \pm 6.1$ & $0.018^{*}$ \\
\hline Stroop test: color reading & $26.0 \pm 13.2$ & $44.5 \pm 35.9$ & 0.905 & $-4.4 \pm 9.5$ & $8.2 \pm 8.1$ & $0.008^{*}$ \\
\hline
\end{tabular}

Continuous variables are presented as mean \pm standard deviation. iNPH: Idiopathic Normal Pressure Hydrocephalus; AD: Alzheimer's Disease; K-BNT: Korean version of Boston Naming Test; RCFT: Rey Complex Figure Test; SVLT: Seoul Verbal Learning Test; COWAT: Controlled Oral Word Association Test.

higher in AD than in iNPH. These results correspond well with earlier studies which reported various CSF biomarkers indicating less AD pathology in iNPH patients than AD patients $[11,29,30]$. After determination of cutoff level of $\mathrm{AD}$ using ROC analysis of CSF biomarkers in $\mathrm{AD}$ and control group, 8 out of 25 iNPH patients (32\%) were classified as having concomitant AD. This is consistent with the overall prevalence of $\mathrm{AD}$ in normal elderly population [31].In contrast to the consistent low $A \beta 42$ level in $\mathrm{iNPH}$, there have been inconsistent reports regarding the T-tau and P-tau levels. Some recent studies using ventricular CSF during shunt procedure or external lumbar drainage (ELD) reported higher T-tau and P-tau level in iNPH patients $[10,14,15]$. On the other hand, a recent report investigating various biomarkers in lumbar and ventricular CSF showed lower T-tau and P-tau level in iNPH than normal control group [16]. Elevated T-tau level has been detected in various diseases causing neuronal injury such as stroke, trauma, hemorrhage and encephalitis [32-34]. Shunt operation and ELD procedure might result in neuronal injury and elevated T-tau and P-tau level in these studies. Cortical neuronal injury from the advanced stage of $\mathrm{iNPH}$ and concomitant AD might affect this discrepancy, as well.

Except for the hippocampal atrophy, all the radiological and clinical symptomatic indicators of iNPH patients including response to CSF drainage did not differ between the two subgroups divided by CSF A $\beta 42$ level. These results are similar to those of previous studies which reported that iNPH patients benefit equally from shunting regardless of the presence of AD pathology [7-9]. Recently a study performed to compare CSF biomarkers and response to ELD showed that none of the biomarker predicted the ELD results [14]. However there have been a few reports that cortical AD pathology and ventricular CSF biomarker for $\mathrm{AD}$ resulted in a less robust response to shunting $[4,10]$. Further long-term follow-up study using simultaneous investigation of AD biomarkers of cortical pathology and ventricular and lumbar CSF might provide some of these answers.

Although there was no difference in general cognitive function between the two subgroups, the initial detailed neuropsychological tests revealed more deficits in attention, visuospatial function and verbal memory in the 
lower CSF A $\beta 42$ group. These domains are well known to be impaired in the early course of $\mathrm{AD}$. Therefore these results suggested that $\mathrm{AD}$ pathology may impact an additive AD-related cognitive dysfunction in iNPH patients regardless of underlying cognitive dysfunction caused by iNPH. In addition to the initial difference, categorical naming and inhibitory executive dysfunctions in the lower CSF A 42 group, which were considered as iNPH-related cognitive dysfunction, were less improved after lumbar puncture compared to the higher CSF A $\beta 42$ group. These results suggested that some portion of the frontal lobe dysfunction in the lower CSF A $\beta 42$ group was possibly caused by the concomitant $\mathrm{AD}$ and not improved after lumbar puncture. In contrast, the frontal lobe dysfunction in the higher CSF A $\beta 42$ group was solely caused by the pathophysiology of iNPH and improved more than the lower CSF A 442 group. This pattern of improvement after lumbar puncture was not reported before but the similar pattern of post-shunt improvement was noted in a previous study which observed improvement of subcortical dysfunction after shunting [10].

We assumed that memory impairment and visuospatial dysfunction in iNPH were mainly caused by concomitant AD which was defined by lower CSF A $\beta 42$. This assumption was usually correct in pure AD but the correlation of the cognitive dysfunction with CSF biomarkers is more complicated in iNPH. For example, in a previous series of $17 \mathrm{iNPH}$ cases, the visuospatial dysfunction was the prominent cognitive feature which was against the classic view of iNPH as a subcortical, frontal type of dementia [35]. Furthermore in a recent study, the decreased CSF A $\beta 42$ was not considered as a biomarker for concomitant AD but a consequence of a reduced brain metabolism secondary to the changed CSF dynamic in iNPH [16]. However, there was neuropathological evidence that the CSF biomarkers for AD correlated with cortical brain biopsy findings indicating $\mathrm{AD}$ [17]. There were also studies showing that the memory deficit as the leading symptom and cortical biopsy findings predicted later development of AD in $\mathrm{iNPH}[36,37]$. Further studies are warranted regarding the correlation between the cognitive symptoms and CSF biomarkers for AD in iNPH.

We should accept that this study has several limitations. One limitation of this study is its relatively small sample size. Another limitation is lack of analysis of long-term follow-up data such as shunting history. The authors also acknowledged that the possible iNPH criteria is inclusive and the elevated T-tau and P-tau levels might be induced by some different circumstances. In addition, normal control subjects were recruited from the clinic and possibly had cognitive complaint more than those recruited from the cohort. Subjects with cognitive complaint are known to have more AD pathology than those without it [38]. This may affect the lack of difference in T-tau and P-tau between AD and control groups. The improvement after lumbar puncture may be affected by the learning effect but there was a report that no learning effect was found in patients with iNPH on any of neuropsychological tests [39].

\section{Conclusions}

Our study suggested that concomitant AD in iNPH patients might contribute to lumbar puncture or shunt unresponsiveness, especially in the field of cognitive dysfunction.

\section{Competing interests}

There are no financial or non-financial competing interests on this study.

\section{Authors' contributions}

TSL, JYC, SAP, YCY, HYL, and SYM carried out the study, analyzed the data and produced the draft. BGK, ISJ and $\mathrm{KH}$ improved on the draft and also helped with the recruitment of patients. All authors read and approved the final manuscript.

\section{Acknowledgements}

This study was supported by grants from the Korea Health 21 R\&D Project, Ministry of Health, Welfare, and Family Affairs, Republic of Korea (HI10C2020) and Korean Health Technology R \& D Project, Ministry for Health, Welfare \& Family Affairs, Republic of Korea (A092004).

\section{Author details}

${ }^{1}$ Department of Neurology, School of Medicine, AjouUniversity, 5 San, Woncheon-dong, Yongtong-gu, Suwon-si, Kyunggi-do 442-749, Republic of Korea. ${ }^{2}$ Department of Neurology, Soonchunhyang University College of Medicine, Bucheon, Republic of Korea. ${ }^{3}$ Department of Neurology, Chung-Ang University College of Medicine, Seoul, Republic of Korea. ${ }^{4}$ Regional Clinical Trial Center, Ajou University Medical Center, Suwon, Republic of Korea.

Received: 20 January 2014 Accepted: 28 March 2014 Published: 1 April 2014

\section{References}

1. Adams RD, Fisher CM, Hakim S, Ojemann RG, Sweet WH: Symptomatic occult hydrocephalus with "Normal" cerebrospinal-fluid pressure.a treatable syndrome. N Engl J Med 1965, 273:117-126.

2. Relkin N, Marmarou A, Klinge P, Bergsneider M, Black PM: Diagnosing idiopathic normal-pressure hydrocephalus. Neurosurgery 2005, 57(3 Suppl):S4-S16. discussion ii-v.

3. Hebb AO, Cusimano MD: Idiopathic normal pressure hydrocephalus: a systematic review of diagnosis and outcome. Neurosurgery 2001, 49(5):1166-1184. discussion 1184-1166.

4. Hamilton R, Patel S, Lee EB, Jackson EM, Lopinto J, Arnold SE, Clark CM, Basil A, Shaw LM, Xie SX, Grady MS, Trojanowski JQ: Lack of shunt response in suspected idiopathic normal pressure hydrocephalus with Alzheimer disease pathology. Ann Neurol 2010, 68(4):535-540.

5. Silverberg GD, Mayo M, Saul T, Rubenstein E, McGuire D: Alzheimer's disease, normal-pressure hydrocephalus, and senescent changes in CSF circulatory physiology: a hypothesis. Lancet Neurol 2003, 2(8):506-511.

6. Silverberg GD, Mayo M, Saul T, Fellmann J, Carvalho J, McGuire D: Continuous CSF drainage in AD: results of a double-blind, randomized, placebo-controlled study. Neurology 2008, 71(3):202-209.

7. Bech-Azeddine R, Hogh P, Juhler M, Gjerris F, Waldemar G: Idiopathic normal-pressure hydrocephalus: clinical comorbidity correlated with cerebral biopsy findings and outcome of cerebrospinal fluid shunting. J Neurol Neurosurg Psychiatry 2007, 78(2):157-161.

8. Golomb J, Wisoff J, Miller DC, Boksay I, Kluger A, Weiner H, Salton J, Graves W: Alzheimer's disease comorbidity in normal pressure hydrocephalus: prevalence and shunt response. J Neurol Neurosurg Psychiatry 2000, 68(6):778-781. 
9. Bech RA, Waldemar G, Gjerris F, Klinken L, Juhler M: Shunting effects in patients with idiopathic normal pressure hydrocephalus; correlation with cerebral and leptomeningeal biopsy findings. Acta Neurochir (Wien) 1999, 141(6):633-639.

10. Patel S, Lee EB, Xie SX, Law A, Jackson EM, Arnold SE, Clark CM, Shaw LM, Grady MS, Trojanowski JQ, Hamilton RH: Phosphorylated tau/amyloid beta 1-42 ratio in ventricular cerebrospinal fluid reflects outcome in idiopathic normal pressure hydrocephalus. Fluids Barriers CNS 2012, 9(1):7.

11. Kapaki EN, Paraskevas GP, Tzerakis NG, Sfagos C, Seretis A, Kararizou E, Vassilopoulos D: Cerebrospinal fluid tau, phospho-tau181 and beta-amyloid1-42 in idiopathic normal pressure hydrocephalus: a discrimination from Alzheimer's disease. Eur J Neurol 2007, 14(2):168-173.

12. Tarnaris A, Toma AK, Chapman MD, Keir G, Kitchen ND, Watkins LD: Use of cerebrospinal fluid amyloid-beta and total tau protein to predict favorable surgical outcomes in patients with idiopathic normal pressure hydrocephalus. J Neurosurg 2011, 115(1):145-150.

13. Agren-Wilsson A, Lekman A, Sjoberg W, Rosengren L, Blennow K, Bergenheim AT, Malm J: CSF biomarkers in the evaluation of idiopathic normal pressure hydrocephalus. Acta Neurol Scand 2007, 116(5):333-339.

14. Leinonen V, Menon LG, Carroll RS, Dello lacono D, Grevet J, Jaaskelainen JE, Black PM: Cerebrospinal fluid biomarkers in idiopathic normal pressure hydrocephalus. Int J Alzheimers Dis 2011, 2011:312526.

15. Tarnaris A, Toma AK, Chapman MD, Petzold A, Kitchen ND, Keir G, Watkins LD: The longitudinal profile of CSF markers during external lumbar drainage. J Neurol Neurosurg Psychiatry 2009, 80(10):1130-1133.

16. Jeppsson A, Zetterberg H, Blennow K, Wikkelso C: Idiopathic normal-pressure hydrocephalus: pathophysiology and diagnosis by CSF biomarkers. Neurology 2013, 80(15):1385-1392.

17. Seppala TT, Nerg O, Koivisto AM, Rummukainen J, Puli L, Zetterberg H, Pyykko OT, Helisalmi S, Alafuzoff I, Hiltunen M, Jääskeläinen JE, Rinne J, Soininen H, Leinonen V, Herukka SK: CSF biomarkers for Alzheimer disease correlate with cortical brain biopsy findings. Neurology 2012, 78(20):1568-1575.

18. McKhann G, Drachman D, Folstein M, Katzman R, Price D, Stadlan EM: Clinical diagnosis of Alzheimer's disease: report of the NINCDS-ADRDA Work Group under the auspices of Department of Health and Human Services Task Force on Alzheimer's Disease. Neurology 1984, 34(7):939-944.

19. Ahn HJ, Chin J, Park A, Lee BH, Suh MK, Seo SW, Na DL: Seoul Neuropsychological Screening Battery-dementia version (SNSB-D): a useful tool for assessing and monitoring cognitive impairments in dementia patients. J Korean Med Sci 2010, 25(7):1071-1076.

20. Larsson A, Wikkelso C, Bilting M, Stephensen H: Clinical parameters in $\mathbf{7 4}$ consecutive patients shunt operated for normal pressure hydrocephalus. Acta Neurol Scand 1991, 84(6):475-482.

21. Krauss JK, Regel JP, Vach W, Jungling FD, Droste DW, Wakhloo AK: Flow void of cerebrospinal fluid in idiopathic normal pressure hydrocephalus of the elderly: can it predict outcome after shunting? Neurosurgery 1997 40(1):67-73. discussion 73-64

22. Blennow $\mathrm{K}$, Wallin A, Agren $\mathrm{H}$, Spenger $\mathrm{C}$, Siegfried J, Vanmechelen E: Tau protein in cerebrospinal fluid: a biochemical marker for axonal degeneration in Alzheimer disease? Mol Chem Neuropathol 1995, 26(3):231-245.

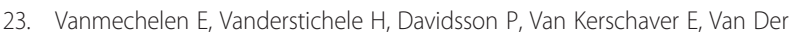
Perre B, Sjogren M, Andreasen N, Blennow K: Quantification of tau phosphorylated at threonine 181 in human cerebrospinal fluid: a sandwich ELISA with a synthetic phosphopeptide for standardization. Neurosci Lett 2000, 285(1):49-52

24. Andreasen N, Hesse C, Davidsson P, Minthon L, Wallin A, Winblad B, Vanderstichele $H$, Vanmechelen $\mathrm{E}$, Blennow K: Cerebrospinal fluid beta-amyloid(1-42) in Alzheimer disease: differences between early- and late-onset Alzheimer disease and stability during the course of disease. Arch Neurol 1999, 56(6):673-680

25. Moon SY, Na DL, Seo SW, Lee JY, Ku BD, Kim SY, Park KW, Shim YS, Youn YC, Chung CS, Cheong HK, Choi SH, Cha KR, Kim JE, Jeong JH: Impact of white matter changes on activities of daily living in mild to moderate dementia. Eur Neurol 2011, 65(4):223-230.

26. Scheltens $P$, Leys $D$, Barkhof $F$, Huglo D, Weinstein HC, Vermersch $P$, Kuiper M, Steinling M, Wolters EC, Valk J: Atrophy of medial temporal lobes on MRI in "probable" Alzheimer's disease and normal ageing: diagnostic value and neuropsychological correlates. J Neurol Neurosurg Psychiatry 1992, 55(10):967-972.
27. Kim H, Na DL: Normative data on the Korean version of the Boston Naming Test. J Clin Exp Neuropsychol 1999, 21(1):127-133.

28. Mattsson N, Zetterberg $H$, Hansson $O$, Andreasen N, Parnetti L, Jonsson M, Herukka S-K, van der Flier WM, Blankenstein MA, Ewers M, Rich K, Kaiser E, Verbeek M, Tsolaki M, Mulugeta E, Rosén E, Aarsland D, Visser PJ, Schröder J, Marcusson J, de Leon M, Hampel H, Scheltens P, Pirttilä T, Wallin A, Jönhagen ME, Minthon L, Winblad B, Blennow K: CSF Biomarkers and Incipient Alzheimer disease in patients with mild cognitive impairment. JAMA: J Am Med Assoc 2009, 302(4):385-393.

29. Wilson RK, Williams MA: The role of the neurologist in the longitudinal management of normal pressure hydrocephalus. Neurologist 2010, 16(4):238-248

30. Lins $\mathrm{H}$, Wichart I, Bancher C, Wallesch CW, Jellinger KA, Rosler N: Immunoreactivities of amyloid beta peptide((1-42)) and total tau protein in lumbar cerebrospinal fluid of patients with normal pressure hydrocephalus. J Neural Transm 2004, 111(3):273-280.

31. Aizenstein HJ, Nebes RD, Saxton JA, Price JC, Mathis CA, Tsopelas ND, Ziolko SK James JA, Snitz BE, Houck PR, Bi W, Cohen AD, Lopresti BJ, DeKosky ST, Halligan EM, Klunk WE: Frequent amyloid deposition without significant cognitive impairment among the elderly. Arch Neurol 2008, 65(11):1509-1517.

32. Hesse C, Rosengren $L$, Andreasen N, Davidsson P, Vanderstichele $H$, Vanmechelen $\mathrm{E}$, Blennow K: Transient increase in total tau but not phospho-tau in human cerebrospinal fluid after acute stroke. Neurosci Lett 2001, 297(3):187-190.

33. Paraskevas GP, Kapaki E, Liappas I, Theotoka I, Mamali I, Zournas C, Lykouras $L$ : The diagnostic value of cerebrospinal fluid tau protein in dementing and nondementing neuropsychiatric disorders. J Geriatr Psychiatry Neurol 2005, 18(3):163-173.

34. Hulstaert F, Blennow K, Ivanoiu A, Schoonderwaldt HC, Riemenschneider M, De Deyn PP, Bancher C, Cras P, Wiltfang J, Mehta PD, Iqbal K, Pottel H, Vanmechelen $E$, Vanderstichele $H$ : Improved discrimination of $A D$ patients using beta-amyloid(1-42) and tau levels in CSF. Neurology 1999, 52(8):1555-1562

35. Bugalho P, Alves $L$, Miguel R, Ribeiro O: Profile of cognitive dysfunction and relation with gait disturbance in Normal Pressure Hydrocephalus. Clin Neurol Neurosurg 2014, 118:83-88

36. Leinonen $V$, Koivisto AM, Savolainen S, Rummukainen J, Tamminen JN Tillgren T, Vainikka S, Pyykko OT, Molsa J, Fraunberg M, Pirttilä T, Jääskeläinen JE, Soininen H, Rinne J, Alafuzoff I: Amyloid and tau proteins in cortical brain biopsy and Alzheimer's disease. Ann Neurol 2010, 68(4):446-453

37. Koivisto AM, Alafuzoff I, Savolainen S, Sutela A, Rummukainen J, Kurki M, Jaaskelainen JE, Soininen H, Rinne J, Leinonen V, Kuopio NPH Registry: Poor cognitive outcome in shunt-responsive idiopathic normal pressure hydrocephalus. Neurosurgery 2013, 72(1):1-8; discussion 8.

38. Visser PJ, Verhey F, Knol DL, Scheltens P, Wahlund LO, Freund-Levi Y, Tsolaki M, Minthon L, Wallin AK, Hampel $H$, Bürger $K$, Pirttila T, Soininen $H$, Rikkert MO, Verbeek MM, Spiru L, Blennow K: Prevalence and prognostic value of CSF markers of Alzheimer's disease pathology in patients with subjective cognitive impairment or mild cognitive impairment in the DESCRIPA study: a prospective cohort study. Lancet Neurol 2009, 8(7):619-627.

39. Solana E, Poca MA, Sahuquillo J, Benejam B, Junque C, Dronavalli M: Cognitive and motor improvement after retesting in normal-pressure hydrocephalus: a real change or merely a learning effect? J Neurosurg 2010, 112(2):399-409.

\section{doi:10.1186/1471-2377-14-66}

Cite this article as: Lim et al:: Evaluation of coexistence of Alzheimer's disease in idiopathic normal pressure hydrocephalus using ELISA analyses for CSF biomarkers. BMC Neurology 2014 14:66. 